\title{
The Pacific Emergency Medicine Mentoring Program: a model for medical mentoring in the Pacific region
}

\section{The Pacific Emergency Medicine Mentoring Program: a model for medical mentoring in the Pacific region}

Running Title: Pacific EM Mentoring

\author{
Authors \\ Georgina Phillips MBBS, FACEM. PhD Scholar ${ }^{1}$, Emergency Physician ${ }^{2}$ \\ Dennis Lee MBBS, MMedEM. Assistant Professor ${ }^{3}$ \\ Shivani Shailin MBBS, MMedEM. Emergency Medicine Consultant ${ }^{4}$ \\ Gerard O’Reilly MBBS, FACEM, MPH MBiostat AStat PhD. Adjunct Clinical Associate \\ Professor $^{1}$, Emergency Physician ${ }^{5}$ \\ Peter Cameron MBBS, MD, FACEM, FIFEM, FCEM (hon), Professor ${ }^{1}$, Academic Director $^{5}$
}

\section{Author contribution}

GP conceived and initiated the research, developed and implemented the survey, collected all data, led and performed data analysis and interpretation, and wrote the paper. DL and SS performed data analysis and interpretation, and critically reviewed the paper for content, GOR and PC provided oversight to the research and critically reviewed the paper for content.

\section{Author institutions}

1. School of Public Health and Preventive Medicine, Monash University, Melbourne, Australia

2. Emergency Department, St. Vincent's Hospital Melbourne, Melbourne, Australia

3. School of Medical Science, College of Medicine, Nursing and Health Sciences, Fiji National University, Suva, Fiji

4. Emergency Department, Colonial War Memorial Hospital, Suva, Fiji

5. Emergency and Trauma Centre, The Alfred Hospital, Melbourne, Australia

This is the author manuscript accepted for publication and has undergone full peer review but has not been through the copyediting, typesetting, pagination and proofreading process, which may lead to differences between this version and the Version of Record. Please cite this article as doi: $10.1111 / 1742-6723.13366$

This article is protected by copyright. All rights reserved. 


\section{Corresponding author}

Dr Georgina Phillips. School of Public Health and Preventive Medicine, Monash University. 553 St. Kilda Rd. Melbourne VIC 3004. Mobile: 0481099461

Word Count: $\quad$ Abstract: $237 \quad$ Main Text: 2550

\section{ABSTRACT}

\section{$\underline{\text { Objectives }}$}

To describe the development and implementation of a Pacific medical mentoring program and to evaluate the program after the first year

\section{Methods}

The mentoring program was adapted from Australasian College for Emergency Medicine (ACEM) resources and involved Australian emergency physicians mentoring Pacific Island Country (PIC) doctors. Using a prospective, cross sectional survey of all participants, researchers collected data that were analysed for content using deductive and inductive methods. Content analysis aimed to generate new concepts that could apply to different components of mentoring, and overarching themes that apply to the mentoring program overall.

$\underline{\text { Results }}$ 
Nineteen doctors participated in the first year of the program; 11 mentees from three different PICs and 8 ACEM Fellow mentors. The survey was completed with a $100 \%$ response rate. Five core themes were identified from the data: vital face-to-face communication (the key to effective communication); supportive personal relationship (valued and desired by mentees); motivating professional relationship (including a regional Pacific network); substantial challenges (time, distance, remote communication); and issues around the mentoring model (goal-orientation, mentor-driven, culture).

\section{Conclusions}

This study suggests a new model of Pacific mentoring that recognises the centrality of the mentoring relationship, and allows for flexible communication, shared responsibility of mentors and mentees as co-drivers, and a broad understanding of goals and timelines. Future programs should incorporate funding for in-person meetings and educational opportunities to enhance contextual and cultural understanding. These lessons can inform future medical mentorship programs across the Pacific.

\section{KEY WORDS}

Mentoring, Pacific Islands, Emergency Medicine

This article is protected by copyright. All rights reserved. 


\section{INTRODUCTION}

Mentoring in medicine contributes to professional development, personal well-being, workplace satisfaction, clinical productivity and women's leadership. $(1,2)$ In emergency medicine (EM), mentoring can lead to greater career satisfaction and longevity.(3) Increasingly, governments and professional training organisations, such as the Australasian College for Emergency Medicine (ACEM) are required to provide mentoring guidelines and support programs for clinicians they credential.(4) Australian government Pacific region health aid programs, including the Pacific Islands Program, now emphasise mentoring and leadership support for clinical capacity development as an essential program component.(5)

EM is an emerging specialty in Pacific Island Countries (PICs).(6) Two PIC universities offer EM specialty training to Diploma and Masters level; University of Papua New Guinea (UPNG) and Fiji National University (FNU). PIC governments enable young doctors to graduate as EM specialists from these programs and expect them to return to their home environments as

This article is protected by copyright. All rights reserved. 
leaders, teachers and advocates. These doctors are often the only specialist EM clinician in their country. As sole practitioners with little peer support, they must establish their credibility, explain the critical importance of their new specialty and take on substantial leadership roles.(7) Burnout and premature career stagnation are substantial risks. In Fiji, surgeons describe substantial levels of occupational stress and burnout, and lack awareness of their mental and physical well-being.(8) Burnout is known to effect EM clinicians,(9) particularly specialists with less experience but high work responsibilities,(10) leading to a high risk of attrition from EM practice.(11)

The Pacific EM Mentoring Program was developed to address these known risks by supporting PIC specialist EM doctors through mentorship with Australian emergency physicians (FACEMs) in a program adapted from ACEM resources, using the ACEM mentoring definition:

"Mentoring describes a relationship based upon mutual trust, respect and encouragement that fosters reflection and learning. It is a series of progressive conversations that empower the mentee to find solutions, work towards professional goals and facilitates leadership development." (4)

Literature on mentoring in EM is scarce, confined to high resource environments and barely addresses mentoring across countries and cultural differences. There are few resources supporting mentorship in resource-limited environments, and adapting best practices from highly developed settings is complex.(12) Although created for the Australasian context, the 
ACEM mentoring resources incorporate common mentorship competencies (13),(14) and toolkits that have been identified as appropriate for a global health setting.(12) As Australasian clinicians and professional medical bodies are increasingly engaged in supportive partnerships and mentoring relationships with PIC colleagues, lessons learnt from a Pacific EM mentoring strategy may assist in future cross discipline programs.

The aim of this paper is twofold; to describe the development and implementation of the Pacific EM mentoring program and to evaluate the program after the first year.

\section{METHODS}

\section{Program development and structure}

The Strengthening Specialist Clinical Services in the Pacific (SSCSiP) program (15) was funded from 2010-2015 by the Australian Government Department of Foreign Affairs to support PICs in planning and implementing specialist clinical services. To coincide with the first FNU EM Masters and 2015 EM Diploma graduates, the SSCSiP program requested visiting FACEMs establish and participate in a mentoring program to support these new EM doctors, with the principle author (GP) as the program lead. The proposed mentees completed a preprogram survey that provided essential background information to shape the mentoring program framework. They reported a high desire for mentoring, although had little personal and often unsatisfactory experience.

This article is protected by copyright. All rights reserved. 
Utilising available literature and the pre-program survey, ACEM mentoring resources were adapted for the Pacific program with these goals: establish formal mentoring relationships; build resources and a sharing platform; and create a network of support for EM leaders around the Pacific. Participating mentors were FACEMs with experience in Fiji, and mentees comprised graduating FNU EM Diploma and Masters students. Prospective mentors provided a biography to mentees, who then identified their three mentor preferences and were matched by the program lead, aiming to complement mentor skills with mentee choice. Bespoke resources included mentee and mentor handbooks and a website (www.empacificmentor.com) with protected pages for uploading and sharing documents. The Pacific EM Mentoring program was launched in June 2016.

\section{Evaluation}

Prospective, cross-sectional evaluation of the program occurred between July to October 2017, and focused on level 1(reaction) and level 2 (learning) from Kirkpatrick's evaluation model.(16) Informed by contemporary mentoring literature, the pre-program survey and components of the mentoring program, a survey tool (Supporting Information) comprising six topic sections and 27 total questions was developed and refined by members of the research team. Pilot testing did not occur due to the very small pool of PIC mentees. The survey was sent to all program participants in paper and electronic form, using in-person, email and social media to maximise participation. Survey topics focused on different components of the program: mentoring relationships; communication issues; outcomes; 
resources; perspectives and knowledge of mentoring; and overall feedback. All questions required anonymous, open, free-text responses and some included simple ratings using a Likert Scale. Surveys with open-ended questions were chosen instead of interviews as the evaluation tool for pragmatic reasons.

\section{Data analysis}

De-identified and mentee/mentor colour-coded survey responses were grouped by topic. Content data analysis was performed using deductive coding whereby pre-identified categories (the survey topics) were applied to the responses, and inductive coding to identify new concepts.(17) Researchers (GP, DL and SS) manually coded the data independently, and then met in-person several times to discuss and agree on the overarching themes, meaning and interpretation of the results. Rated responses are reported as medians and range.

\section{Ethics}

This study was approved by the Monash University Human Research and Ethics Committee (MUHREC project No. 9927) and written informed consent was obtained from all participants.

\section{RESULTS}

This article is protected by copyright. All rights reserved. 
Nineteen doctors participated in the first year of the mentoring program; 8 FACEM mentors, and 11 mentees from three different PICs. The survey was returned with a $100 \%$ response rate from both mentees and mentors, with open-ended response lengths ranging from short phrases to several sentences. Findings from each topic section are presented initially, with illustrative quotes in Table 2. Five core overarching themes were identified from the data and are presented in Table 3.

\section{Findings by survey topic}

\section{Mentoring Relationship}

Mentees described two types of relationship; personally supportive and professionally enhancing. Valuable relationship qualities included trust, approachability, support and expertise. Mentors used educational opportunities to meet their mentees in person, usually in their home country. Almost all mentees had met their mentor in-person at least once in the previous 12 months; an experience highly valued by both participants.

The inability to meet in person, distance and time challenges of establishing and maintaining remote communication, and contrasting mentee / mentor expectations were key barriers to establishing the mentoring relationship. Scores for relationship, matching, gender balance, cultural / language issues and participants are presented in Table 1.

\section{Communication Issues}

This article is protected by copyright. All rights reserved. 
Only one mentee-mentor pair communicated (by any means) more than once a month. Most had infrequent communication at the lower end of a range between every 1-12 months without a clear plan or structure; the main barriers attributed to distance and time. Although social media was used a little (facebook, viber, messenger, skype), the main method of remote communication was email, despite limitations.

A disparity emerged between mentees and mentors regarding communication method and frequency. On the whole, mentees reported that their hopes and expectations for communication were not met compared to mentors, who were more likely to report expectations met or express uncertainty. Additionally, mentees were more likely to report keeping a record of communication with their mentor.

The most positive aspect of mentor-mentee communication was to establish a sense of connection, particularly through face-to-face meetings. Participants valued both the supportive and professionally helpful nature of the relationship.

\section{Outcomes}

Most mentees reported that they had set personal and professional development goals (including education, research, and leadership) and that these largely had been achieved. In clear contrast, mentors described no formal goal-setting and felt that no mentee goals were achieved. Only one pair used a known framework to set goals.

This article is protected by copyright. All rights reserved. 
Around half of participants described two types of positive outcomes; the establishment of a personal relationship and development at a personal or professional level. No participant reported any negative consequences from the mentoring program.

\section{$\underline{\text { Resources }}$}

The simple resources provided were barely used by either mentees or mentors, particularly the handbooks. Mentees used the website more, but for both participants, there was utility at the start, but minimal ongoing access. Some mentees reported challenges with IT access and use. Participants did not access any other resources about mentoring and the majority thought adequate resources have been provided for the program.

\section{Perspectives and Knowledge}

A clear difference emerged again between mentees and mentors in whether they reported changes to knowledge and perspective about mentoring. Mentees learnt about role modelling and gained exposure to new ideas, but also appreciated the difficulties of long distance and cross-cultural mentoring. Mentors, on the whole, did not feel that they had gained a new appreciation of mentoring, except to acknowledge the challenge of remote mentoring

Overall feedback

This article is protected by copyright. All rights reserved. 
The overall feeling about the program was positive with a sense of hope and enthusiasm for the future. Mentees gave an overall rating median score of 8 (range 3-10), and mentors 7 (range 3-9) on a scale between 0 (poor program) to 10 (fantastic program).

The program was valued as a mechanism for developing a personal relationship that is supportive and aids development and learning, and as a framework for establishing a regional Pacific connection. Commitment level was identified as a barrier to program progression.

\section{Overarching themes}

Five core themes were identified from the data: vital face-to-face communication; supportive personal relationship; motivating professional relationship; substantial challenges; and issues around the mentoring model.

Components of each core theme, with illustrative quotes are presented in Table 3. All themes interact with and influence the other.

\section{DISCUSSION}

\section{Principle Findings}

This is the first descriptive and qualitative analysis of a multi-country medical mentoring program for the Pacific region. This program exists to provide support and advice in the early EM specialty phase where the future is uncertain. As a result, Pacific EM doctors feel 
supported and develop professionally within a regional network. The joint enterprise of Pacific EM mentorship, mutual engagement by participating FACEMs and PIC doctors, and shared repertoire of resources, insights and reflection through this evaluation have built a 'community of practice' for EM in the Pacific. (18)

Aside from the program adaption and implementation, the main outcome of this analysis are the core themes that illuminate how a mentoring model operates in the Pacific environment. Within the overarching context of a structured, goal-oriented and mentee driven program, a mentee-mentor relationship can be established that does not conform to this conventional model. Despite the challenges of time, distance and remote communication, mentors and mentees can use infrequent face-to-face opportunities to establish a supportive personal connection and motivating professional relationship. These relationships in themselves can be seen as a valuable outcome, outside the paradigm of goal-setting and highly structured communication patterns.

We observe that the Pacific Islands cultural context emphasises the centrality of personal networks and relationships.(19) In high-resource contexts, a doctor expects to develop professionally and be rewarded by ascending a visible career ladder if they achieve professional goals and meet self-defined targets. In the Pacific, career progression can be limited, opaque and sometimes tortuous; often subject to funding, scholarships, unplanned opportunity, family events, personalities and employment structures beyond their control. We suggest that PIC EM doctors therefore see the establishment of a personal and 
professional supportive relationship as a key achievement and are more likely to be satisfied by this connection as an end in itself. Trust and approachability are key components of the supportive relationship, particularly for some mentees who struggled with their selfreported cultural tendency to keep issues to themselves or not bother their senior mentor with communication requests.

\section{Implications}

These findings can be used to inform the development and conduct of successful regional medical mentorship programs across the Pacific and build other supportive communities of practice. In order to establish the central and supportive personal relationship, more frequent face-to-face communication is essential and should be prioritised. Responding to the disparity detected between mentors and mentees, we recommend active preparation for mentoring through group education opportunities that create a shared understanding of the function, hopes and expectations of all participants. Mentors then gain a deeper understanding of unique Pacific contextual challenges, which differ from how they perform mentorship in their Australian environment. Expanding the program model to consciously embed the principles and process of Professional Identity Formation (20) can elevate the impact of mentoring for young and isolated new EM (and other discipline) specialists and enhance their own role as mentors in the future. This study recommends a new Pacific model of mentoring that focuses on personal relationships, allows for flexible 
communication, shared responsibility between mentors and mentees as 'co-drivers', and a broad understanding of goals and time-lines.

Unambiguous challenges from time, distance and communication technologies will remain. Given the minimal utility, available resources such as mentoring booklets or the bespoke website remain a low priority for change or adaptation.

\section{Comparison with other studies}

Our study found positive effects of mentoring on professional and personal development which are consistent with other studies. A large qualitative study of mentoring schemes in the UK found three key areas of benefit: professional practice, personal well-being and professional/personal development.(1) Similarly, more overarching reviews of the literature have found medical mentoring to assist with professionalism, research skills, confidence and career satisfaction, $(3,21)$ which were also areas of benefit identified in our study.

The primacy of establishing a personal connection between mentor and mentee is noted in other studies,(22) where, as in our Pacific study, the mentor characteristics of responsiveness, availability and expert knowledge are highly valued.(23) Several mentoring models from high resource countries explored the use of 'e-mentoring' or remote mentoring, noting both potential benefits such as crossing barriers of geography, gender, race and hierarchy, $(24,25)$ and real challenges of technology and communication timeliness.(25) These international studies suggest that remote communication may only complement the trust and rapport achieved through dynamic face-to-face interactions. Our 
study lends additional evidence to the need for direct personal interaction for a meaningful mentoring relationship.

Mentoring across cultures and countries has received little attention in the literature. A model incorporating off-site mentors, developed to address minority group (including Pacific Islander) needs in the USA confirmed the importance of contextual adaption to enable supportive relationships.(26) Our study uncovered different expectations between mentors and mentees, where cultural differences and insufficient mentor/mentee preparation may have played a role. The importance of formal training and cultural awareness for research mentorship in Low and Middle Income Countries has been recognised (27) and highlights a gap in our own program. Whilst generational differences may have influenced IT use (28), our program also highlighted distance, time differences and simple internet connectivity as additional communication barriers that may be unique to the Pacific and other limited resource contexts.

\section{Strengths and limitations}

The complete response rate in our study incorporates all possible perspectives on the mentoring program and lends validity to the study findings. Furthermore, data analysis and interpretation was performed by three researchers to reduce bias, and collaboratively with Pacific EM doctors, one of whom participated in the mentoring program. By embedding the Pacific perspective deeply in to the data interpretation, the study speaks with particular 
local meaning, and contributes to a model of respectful, equality-based research between high and lower resource environments, (29) particularly in the Pacific region. (30) It is possible that mentees felt obliged to report positive outcomes through a cultural tendency to avoid disappointing or shaming their seniors, particularly as respected international colleagues. Not all mentees reported positive outcomes and some gave frank and revealing insights. This mix of responses adds integrity to the data although cannot reveal underlying gender, power and cultural influences on participants' responses.

The small participant number overall was a potential limitation of the study, as was the use of an unpiloted survey tool to garner qualitative data. The written questionnaire format enabled complete participation across several PIC sites, and rigorous content analysis assisted to maximise the qualitative interpretation and final message of the study.

\section{CONCLUSION}

Medical mentoring can be implemented between Australia and the Pacific region, with a model that supports the centrality of personal relationships through in-person communication, shares ownership between mentors and mentees, broadens understanding of goals and timelines, and builds new regional communities of practice. These lessons can be adapted across clinical health disciplines where collegiate relationships exist between Australasia and PICs and requests for more formalised programs of mentoring and support are desired. The model of Pacific Mentoring demonstrated by this study may also be better 
suited to other programs that seek to support clinicians working in challenging contexts and different or remote cultural environments.

\section{ACKNOWLEDGEMENTS}

We would like to acknowledge all participating mentees and mentors.

Competing Interests: Authors GP, GOR and PC are section editors of EMA.

\section{REFERENCES}

1. Steven A, Oxley J, Fleming WG. Mentoring for NHS doctors: perceived benefits across the personal-professional interface. J. R. Soc. Med. 2008; 101(11): 552-557.

2. Pope JE. Mentoring women in medicine: a personal perspective. Lancet 2018; 391(10120): 520-521.

3. Yeung M, Nuth J, Stiell IG. Mentoring in emergency medicine: the art and the evidence. CJEM 2010; 12(2): 143-149.

4. Australasian College for Emergency Medicine; Mentoring at ACEM. Available from URL: https://acem.org.au/Content-Sources/Members/Advancing-My-Career (Accessed 11 April 2019) 5. Australian Government Department of Foreign Affairs and Trade (DFAT). Royal Australasian College of Surgeons (RACS) Pacific Islands Program. Available at URL: https://www.surgeons.org/forthe-public/racs-global-health/pacific-island-countries/ (Accessed 11 April 2019)

6. International Federation for Emergency Medicine; History and Member organisations. Available at URL: https://www.ifem.cc/ (Accessed 11 April 2019)

This article is protected by copyright. All rights reserved. 
7. Bae C, Geduld H, Wallis LA, Smit DV, Reynolds T. Professional needs of young Emergency Medicine specialists in Africa: Results of a South Africa, Ethiopia, Tanzania, and Ghana survey. Af. J. Emerg. Med. 2016; 6(2): 94-99.

8. Patel R, Huggard P, van Toledo A. Occupational stress and burnout among surgeons in Fiji. Front. Public Health 2017; 5: 41.

9. Arora M, Asha S, Chinnappa J, Diwan AD. Review article: burnout in emergency medicine physicians. Emerg. Med. Australas. 2013; 25(6): 491-495.

10. Rajan S, Engelbrecht A. A cross-sectional survey of burnout amongst doctors in a cohort of public sector emergency centres in Gauteng, South Africa. Af. J. Emerg. Med. 2018;.8(3): 95-99.

11. Folscher L-L. Care for the Carers. Af. J. Emerg. Med. 2014; 4(4): 167-169.

12. Hansoti B, Kalbarczyk A, Hosseinipour MC, et al. Global Health Mentoring Toolkits: A Scoping Review Relevant for Low-and Middle-Income Country Institutions. Am. J. Trop. Med. Hyg. 2018; 100(1_Suppl): 48-53.

13. Clutterbuck D. Establishing and maintaining mentoring relationships: An overview of mentor and mentee competencies. SA. Journal of Human Resource Management. 2005; 3(3): 2-9.

14. Hamer DH, Hansoti B, Prabhakaran D, et al. Global health research mentoring competencies for individuals and institutions in low-and middle-income countries. Am. J. Trop. Med. Hyg. 2018; 100(1_Suppl): 15-19.

15. Strengthening Specialised Clinical Services in the Pacific (SSCSiP) program. [Evaluation report and management response. 11 November 2015]. Available at URL: https://dfat.gov.au/about-

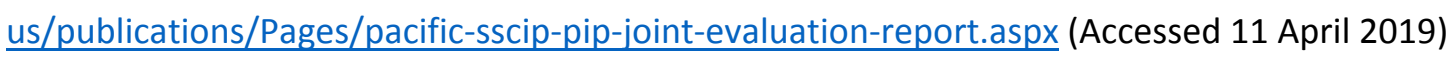

16. Bates R. A critical analysis of evaluation practice: the Kirkpatrick model and the principle of beneficence. Eval Program Plann 2004; 27(3):341-7.

This article is protected by copyright. All rights reserved. 
17. Hansen EC. Successful qualitative health research: a practical introduction. NSW, Australia: Allen and Unwin, 2006.

18. Ranmuthugala G, Plumb JJ, Cunningham FC, Georgiou A, Westbrook JI, Braithwaite J. How and why are communities of practice established in the healthcare sector? A systematic review of the literature. BMC Health Serv Res 2011; 11(1):273.

19. Capstick S, Norris P, Sopoaga F, Tobata W. Relationships between health and culture in Polynesia-A review. Soc Sci Med 2009; 68(7):1341-8.

20. Cruess RL, Cruess SR, Boudreau JD, Snell L, Steinert Y. Reframing Medical Education to Support Professional Identity Formation. Acad Med 2014; 89(11):1446-51.

21. Sambunjak D, Straus SE, Marusic A. Mentoring in academic medicine: a systematic review. JAMA 2006; 296(9): 1103-1115.

22. Sambunjak D, Straus SE, Marusic A. A systematic review of qualitative research on the meaning and characteristics of mentoring in academic medicine. J. Gen. Intern. Med. 2010; 25(1): 72-78.

23. Jackson VA, Palepu A, Szalacha L, Caswell C, Carr P, Inui T. "Having the right chemistry": a qualitative study of mentoring in academic medicine. Acad. Med. 2003; 78: 328-334.

24. Bierema LL, Merriam SB. E-mentoring: Using computer mediated communication to enhance the mentoring process. Innov. High. Educ. 2002; 26(3): 211-227.

25. Griffiths M, Miller H. E-mentoring: does it have a place in medicine? Postgrad. Med. J. 2005; 81(956): 389-390.

26. Lewellen-Williams C, Johnson VA, Deloney LA, Thomas BR, Goyol A, Henry-Tillman R. The POD: a new model for mentoring underrepresented minority faculty. Acad. Med. 2006; 81(3): 275279.

This article is protected by copyright. All rights reserved. 
27. Lescano AG, Cohen CR, Raj T, et al. Strengthening mentoring in low-and middle-income countries to advance global health research: an overview. Am. J. Trop. Med. Hyg. 2019;

100(1_Suppl):3-8.

28. Mohr NM, Moreno-Walton L, Mills AM, et al. Generational influences in academic emergency medicine: teaching and learning, mentoring, and technology (part I). Acad. Emerg. Med. 2011; 18(2): 190-199.

29. Beran D, Byass $P$, Gbakima A, et al. Research capacity building-obligations for global health partners. Lancet Glob. Health 2017; 5(6): e567-e568.

30. Ekeroma A. Collaboration as a tool for building research capacity in the Pacific Islands. Ann. Hum. Biol. 2018; 45(3): 295.

Table 1. Median scores for relationship issues

\begin{tabular}{|llll|}
\hline Category & $\begin{array}{l}\text { Mentee Score } \\
\text { (Median, } \\
\text { range) } \\
\mathrm{n}=11\end{array}$ & $\begin{array}{l}\text { Mentor Score } \\
\text { (median, } \\
\text { range) } \\
\mathrm{n}=11\end{array}$ & Quotes \\
\hline $\begin{array}{l}\text { Overall relationship } \\
\text { 0=no relationship } \\
5=\text { functional but formal } \\
10 \text { prof / personally close }\end{array}$ & $5(3-10)$ & $5(0-9)$ & \\
\hline $\begin{array}{l}\text { Matching } \\
\text { 0=did not work } \\
5=a d e q u a t e \\
10=\text { perfect match }\end{array}$ & $7(5-10)$ & $7(4-8)$ & $\begin{array}{l}\text { "One mentee matched well. Second } \\
\text { mentee I had less in common with \& } \\
\text { wondered whether he would have } \\
\text { benefitted from a male mentor" } \\
\text { (mentor) }\end{array}$ \\
\hline Participants (mentees & $8.5(5-10)$ & $7(5-10)$ & "I wish I had mentoring from the time I \\
\hline
\end{tabular}

This article is protected by copyright. All rights reserved. 


\begin{tabular}{|c|c|c|c|}
\hline $\begin{array}{l}\& \text { mentors) } \\
0=\text { totally wrong } \\
5=\text { adequate selection } \\
10=\text { perfect selection }\end{array}$ & & & $\begin{array}{l}\text { joined the program from Diploma level. } \\
\text { This would have made a huge difference } \\
\text { in my program as well as for my } \\
\text { professional development" (mentee) }\end{array}$ \\
\hline $\begin{array}{l}\text { Gender balance } \\
0=\text { excluded by gender } \\
5=\text { neutral } \\
10=\text { perfect gender balance }\end{array}$ & $5(5-10)$ & $5(2-7)$ & $\begin{array}{l}\text { "We had adequate male and female } \\
\text { balance" (mentee) }\end{array}$ \\
\hline $\begin{array}{l}\text { Language and culture } \\
0=\text { difference ruined } \\
\text { relationship } \\
5=\text { neutral } \\
10=\text { crucial to good } \\
\text { relationship }\end{array}$ & $5(5-10)$ & $5(4-6.5)$ & $\begin{array}{l}\text { "No language issues, cultural } \\
\text { differences not very major" (mentor) }\end{array}$ \\
\hline
\end{tabular}

Table 2. Illustrative quotes per content topic section

\begin{tabular}{|ll|}
\hline $\begin{array}{l}\text { Content topic } \\
\text { section }\end{array}$ & Illustrative quotes \\
\hline $\begin{array}{l}\text { Mentoring } \\
\text { Relationship }\end{array}$ & $\begin{array}{l}\text { "My mentor is a great guy and he inspires a lot of good things in me. He leads by } \\
\text { example. He has made good effort to come and spend time with me" (mentee) } \\
\text { "My mentor is there for professional and academic support" (mentee) } \\
\text { "Initially I thought this would not work out due to distance and our busy work hours, } \\
\text { but teaching opportunities provided a medium to communicate and meet" (mentee) } \\
\text { "Communication is difficult because TIME is too congested with work as I am alone }\end{array}$ \\
\hline
\end{tabular}

This article is protected by copyright. All rights reserved. 


\begin{tabular}{|c|c|}
\hline & $\begin{array}{l}\text { and trying very hard to manage my time between work and family. So far no time } \\
\text { for SELF" (mentee) } \\
\text { "I have found this relationship difficult and not what I had hoped for. The reason for } \\
\text { this is that I have not been in constant contact with my mentor and our meetings } \\
\text { have only been very brief" (mentee) } \\
\text { "Inability to be completely honest especially talk about my personal issues. Not } \\
\text { enough time to build a really open relationship" (mentee) } \\
\text { "It is very difficult when the Mentees are the ones that are supposed to drive the } \\
\text { relationships but they are very busy" (mentor) }\end{array}$ \\
\hline $\begin{array}{l}\text { Communication } \\
\text { Issues }\end{array}$ & $\begin{array}{l}\text { "Initially I tried to plan time to get together on skype or viber through emails....but it } \\
\text { got a bit frustrating because it was hard to arrange the right time and most of the } \\
\text { emails initially were just sent as greetings and trying to arrange time" (mentee) } \\
\text { "Emails were not that good. It's difficult to communicate properly when you are } \\
\text { talking about important topics" (mentee) } \\
\text { "Method of communication - difficult to communicate via emails only, (this) makes } \\
\text { it difficult to gauge how the mentor-mentee relationship works as I do not know my } \\
\text { mentor very well" (mentee) } \\
\text { "I would like to communicate more but am worried that it will make me seem weak. } \\
\text { I feel my mentor has a lot more important things to address" (mentee) } \\
\text { "It has not been as frequent as I think it should have been but the time we have } \\
\text { spent together was valuable" (mentee) } \\
\text { "This was left open ended by me for them to contact as needed. They really did not } \\
\text { contact without me initiating contact" (mentor) } \\
\text { "Frequency appropriate I think, but not much further in the way of how goals are } \\
\text { progressing" (mentor) } \\
\text { "I guess it would be nice if we could have face to face discussions. Email's at times } \\
\text { so impersonal and I had enjoyed our conversation in the beginning...." (mentee) }\end{array}$ \\
\hline Outcomes & $\begin{array}{l}\text { "Yes. 1) Leadership development. 2) Medical education skills. 3) Professional } \\
\text { development" (mentee) } \\
\text { "No, I don't think so, but we discussed; Career progression, personal satisfaction, } \\
\text { desire to get involved with teaching" (mentor) } \\
\text { "I have become more confident in expressing myself to others. I have been more } \\
\text { confident in achieving goals" (mentee) } \\
\text { "Development and maintenance of a relationship" (mentor) }\end{array}$ \\
\hline Resources & $\begin{array}{l}\text { "No. I apologise for not reading the booklet. I did not make time to read the } \\
\text { handbook" (mentee) } \\
\text { "I did briefly at the start. Just got busy and it slipped from my consciousness" } \\
\text { (mentor) }\end{array}$ \\
\hline $\begin{array}{l}\text { Perspectives and } \\
\text { Knowledge }\end{array}$ & $\begin{array}{l}\text { "Yes, the way I get useful advice, now I am trying to use that at work and give } \\
\text { clinical and non-clinical advice to doctors on shift with me when I am left shift in- } \\
\text { charge" (mentee) } \\
\text { "I think it has shown me the limitations of having a mentorship program from } \\
\text { overseas. I think it is easier to mentor someone when you are directly observing } \\
\text { them at work" (mentee) } \\
\text { "It challenges my cultural belief of holding issues close to myself and allowing me to } \\
\text { share" (mentee) }\end{array}$ \\
\hline
\end{tabular}




\begin{tabular}{|l|l|}
\hline & "The distance factor is a challenge - this issue has been reinforced" (mentor) \\
\hline Overall Feedback "Improves relationship with other more experienced EM clinicians. Gives hope that \\
we can be like them one day: ie. influential in our work to help bring out change" \\
(mentee) \\
"It is the first of its kind that has been initiated for the Pacific EM doctors and gives \\
us hope for the future of EM for us, where we face isolation and alienation from \\
other specialties" (mentee) \\
"Increased investment in an individual and the Pacific" (mentor) \\
"Distance and communication barriers - when mentor is away, everything starts to \\
slow down and progress is slow" (mentee) \\
"From a personal perspective I don't feel as though I have contributed as much as I \\
could have and should have been more pro-active in chasing up my mentee to \\
ensure we met regularly to progress the program" (mentor)
\end{tabular}

Table 3. Five core overarching themes

This article is protected by copyright. All rights reserved. 


\begin{tabular}{|c|c|}
\hline Core Theme & Illustrative Quotes \\
\hline \multicolumn{2}{|l|}{ Vital face-to-face communication } \\
\hline $\begin{array}{l}\text { - Key to effective communication } \\
\text { - Core to the ability to establish the } \\
\text { relationship, particularly when the pairs } \\
\text { don't know each other well } \\
\text { - Highly desired from all participants, } \\
\text { particularly the mentees } \\
\text { - Largely only occurring through } \\
\text { opportunistic educational visits, or through } \\
\text { self-funded means }\end{array}$ & $\begin{array}{l}\text { "When I saw them in person the relationship \& } \\
\text { interaction was good but there was little interaction } \\
\text { when not in person" (mentor) } \\
\text { "I wish we had a few more gatherings like the (face- } \\
\text { to-face) workshop to allow us to familiarise } \\
\text { ourselves with our mentors" (mentee) } \\
\text { "Actually meeting in person on his visits to Fiji... I } \\
\text { prefer face to face. You get more verbal as well as } \\
\text { physical cues that way" (mentee) } \\
\text { "I think we really capitalized on his visits to Fiji to } \\
\text { meet his university students" (mentor) }\end{array}$ \\
\hline \multicolumn{2}{|l|}{ Supportive personal relationship } \\
\hline $\begin{array}{l}\text { - Highly valued by the mentees } \\
\text { - Approachability is a component of this } \\
\text { - Social connection is also important } \\
\text { - Mentees who only have a formal } \\
\text { relationship wish for more of a personal, } \\
\text { informal connection }\end{array}$ & $\begin{array}{l}\text { "I have got someone who I can discuss work related } \\
\text { issues when I feel that it cannot be discussed in the } \\
\text { department" (mentee) } \\
\text { "I have been able to express some of my aspirations } \\
\text { and hopes for my training. I am comfortable enough } \\
\text { to talk about what happens at home with my family" } \\
\text { (mentee) } \\
\text { "I would prefer a more informal relationship than } \\
\text { the one I have currently" (mentee) }\end{array}$ \\
\hline \multicolumn{2}{|l|}{ Motivating professional relationship } \\
\hline $\begin{array}{l}\text { - } \quad \text { Education and research development are } \\
\text { valued outcomes } \\
\text { - The experienced mentor provides an } \\
\text { important role model for mentees } \\
\text { - Both mentors and mentees recognise the } \\
\text { importance of building leadership skills } \\
\text { - The program and relationship has been } \\
\text { critical to initiate and build a Pacific } \\
\text { regional network }\end{array}$ & $\begin{array}{l}\text { "..Assistance with research and EBM education" } \\
\text { (mentee) } \\
\text { "I think having senior and experienced mentors } \\
\text { really helps, because they have insight in the steps } \\
\text { we are going through; professionally as well as } \\
\text { personally" (mentee) } \\
\text { "Initial discussions and getting to know a very } \\
\text { intelligent, competent and high functioning } \\
\text { colleague who is becoming a leader in her own } \\
\text { country" (mentor) } \\
\text { "Increased investment in Pacific region and hopefully } \\
\text { longitudinal relationship and involvement in another } \\
\text { Pacific nation" (mentor) } \\
\text { "It keeps you in touch with Emergency Department } \\
\text { family around the Pacific. Mentors involved can } \\
\text { guide us with difficulties faced" (mentee) }\end{array}$ \\
\hline \multicolumn{2}{|l|}{ Substantial challenges } \\
\hline $\begin{array}{l}\text { - Distance is a barrier to establishing the } \\
\text { relationship } \\
\text { - Time pressures limit communication }\end{array}$ & $\begin{array}{l}\text { "The distance significantly affected relationship." } \\
\text { (mentor) } \\
\text { "Initially we tried to have voice conversations but } \\
\text { that didn't work out so well because he would be }\end{array}$ \\
\hline
\end{tabular}




\begin{tabular}{|c|c|}
\hline $\begin{array}{l}\text { opportunities } \\
\text { Remote communication presents unique } \\
\text { barriers to effective communication }\end{array}$ & $\begin{array}{l}\text { busy at work or I would be busy and it would be hard } \\
\text { to make set times because of time differences" } \\
\text { (mentee) } \\
\text { "I live in a country with the worst most expensive } \\
\text { internet connection" (mentee) }\end{array}$ \\
\hline \multicolumn{2}{|l|}{ Issues around the Mentoring Model } \\
\hline $\begin{array}{l}\text { - The program structure (around goal- } \\
\text { setting, mentor-driven and formalised } \\
\text { communication) was not generally adhered } \\
\text { to } \\
\text { - } \quad \text { Mentors and mentees had difference } \\
\text { expectations and understanding of } \\
\text { mentoring } \\
\text { - Resources were developed but barely used } \\
\text { - including contemporary communication } \\
\text { technologies } \\
\text { - Attitudes and motivation influenced the } \\
\text { quality of the relationship } \\
\text { Culture plays a role, but is not well defined }\end{array}$ & $\begin{array}{l}\text { "Many (Pacific Islanders) I know are not proactive in } \\
\text { pursuing ongoing contact. This makes being a } \\
\text { mentor tricky as you have to continually seek them } \\
\text { out, while I feel it should be the other way around" } \\
\text { (mentor) } \\
\text { "Even in an Australian context, I don't think mentees } \\
\text { necessarily grasp the concept of a mentoring } \\
\text { relationship as most of them have not had } \\
\text { experience before" (mentor) } \\
\text { "Feel that relationship is more mentor driven; } \\
\text { realise that this may be due to cultural factors. Hope } \\
\text { that relationship adequately addressing mentee } \\
\text { needs" (mentor) } \\
\text { "I believe the problem is on my part. I am not } \\
\text { responding to emails or social media as often as I } \\
\text { should" (mentee) } \\
\text { "..and mentoring in the Pacific should ideally come } \\
\text { from Pacific Islanders as they would understand } \\
\text { cultures / beliefs which I think plays a big role" } \\
\text { (mentee) } \\
\text { "I am unsure if my mentee fully understands the } \\
\text { role of the mentoring relationship, or if there are } \\
\text { some cultural differences making mutual } \\
\text { understanding more challenging" (mentor) }\end{array}$ \\
\hline
\end{tabular}




\title{
The Pacific Emergency Medicine Mentoring Program: a model for medical mentoring in the Pacific region
}

Running Title: Pacific EM Mentoring

\author{
Authors \\ Georgina Phillips MBBS, FACEM. PhD Scholar ${ }^{1}$, Emergency Physician ${ }^{2}$ \\ Dennis Lee MBBS, MMedEM. Assistant Professor ${ }^{3}$ \\ Shivani Shailin MBBS, MMedEM. Emergency Medicine Consultant ${ }^{4}$ \\ Gerard O’Reilly MBBS, FACEM, MPH MBiostat AStat PhD. Adjunct Clinical Associate \\ Professor $^{1}$, Emergency Physician ${ }^{5}$ \\ Peter Cameron MBBS, MD, FACEM, FIFEM, FCEM (hon), Professor $^{1}$, Academic Director $^{5}$
}

\section{Author contribution}

GP conceived and initiated the research, developed and implemented the survey, collected all data, led and performed data analysis and interpretation, and wrote the paper. DL and SS performed data analysis and interpretation, and critically reviewed the paper for content, GOR and PC provided oversight to the research and critically reviewed the paper for content.

\section{Author institutions}

1. School of Public Health and Preventive Medicine, Monash University, Melbourne, Australia

2. Emergency Department, St. Vincent's Hospital Melbourne, Melbourne, Australia

3. School of Medical Science, College of Medicine, Nursing and Health Sciences, Fiji National University, Suva, Fiji

4. Emergency Department, Colonial War Memorial Hospital, Suva, Fiji

5. Emergency and Trauma Centre, The Alfred Hospital, Melbourne, Australia

\section{Corresponding author}

Dr Georgina Phillips. School of Public Health and Preventive Medicine, Monash University. 553 St. Kilda Rd. Melbourne VIC 3004. Mobile: 0481099461

Word Count: $\quad$ Abstract: $237 \quad$ Main Text: 2550 


\section{University Library}

\section{- M M N E R VA A gateway to Melbourne's research publications}

Minerva Access is the Institutional Repository of The University of Melbourne

Author/s:

Phillips, G;Lee, D;Shailin, S;O'Reilly, G;Cameron, P

Title:

The Pacific Emergency Medicine Mentoring Program: A model for medical mentoring in the Pacific region.

Date:

2019-12

Citation:

Phillips, G., Lee, D., Shailin, S., O'Reilly, G. \& Cameron, P. (2019). The Pacific Emergency Medicine Mentoring Program: A model for medical mentoring in the Pacific region.. Emerg Med Australas, 31 (6), pp.1092-1100. https://doi.org/10.1111/1742-6723.13366.

Persistent Link:

http://hdl.handle.net/11343/286248 